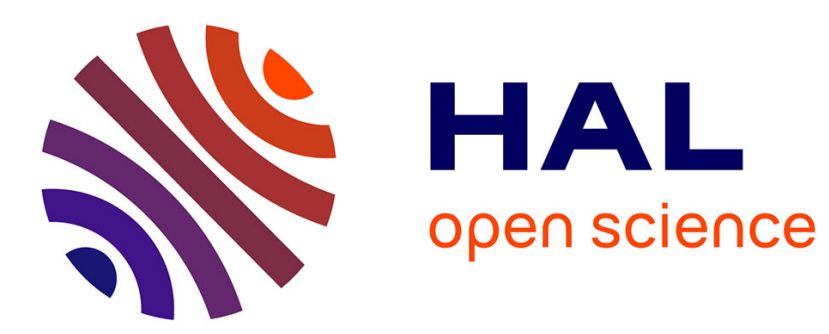

\title{
Micromechanical high-doses radiation sensor with bossed membrane and interferometry optical detection
}

\author{
Isabella Augustyniak, P Knapkiewicz, K Sarelo, Jan Dziuban, Émilie
}

Debourg, Patrick Pons, M Olszacki

\section{- To cite this version:}

Isabella Augustyniak, P Knapkiewicz, K Sarelo, Jan Dziuban, Émilie Debourg, et al.. Micromechanical high-doses radiation sensor with bossed membrane and interferometry optical detection. Sensors and Actuators A: Physical , 2015, 232, pp. 353-358. 10.1016/j.sna.2015.05.006 . hal-01237541

\section{HAL Id: hal-01237541 \\ https://hal.science/hal-01237541}

Submitted on 9 Dec 2015

HAL is a multi-disciplinary open access archive for the deposit and dissemination of scientific research documents, whether they are published or not. The documents may come from teaching and research institutions in France or abroad, or from public or private research centers.
L'archive ouverte pluridisciplinaire HAL, est destinée au dépôt et à la diffusion de documents scientifiques de niveau recherche, publiés ou non, émanant des établissements d'enseignement et de recherche français ou étrangers, des laboratoires publics ou privés. 


\title{
Micromechanical high-doses radiation sensor with bossed membrane and interferometry optical detection
}

\author{
I. Augustyniaka, , P. Knapkiewicz ${ }^{\mathrm{a}}$, K. Sareło ${ }^{\mathrm{a}}$, J.A. Dziubann, E. Debourg ${ }^{\mathrm{b}}$, P. Pons ${ }^{\mathrm{b}, \mathrm{c}}$, \\ M. Olszacki ${ }^{\mathrm{d}}$
}

\begin{abstract}
a Wrocław University of Technology, Faculty of Microsym Electronics and Photonics, Janiszewskiego str. 11/17, 50-372 Wrocław, Poland

b The National Center for Scientific Research, LAAS, BP 54200, 31031 Toulouse cedax 4, France

c Univ de Toulouse, LAAS, F-31400 Toulouse, France

d National Center for Nuclear Research, Radiation Detection Physics Division, Andrzeja Sołtana str. 7, 05-400

Otwock, Poland
\end{abstract}

\begin{abstract}
A b s t r a c t
The silicon-glass MEMS high dose radiation sensor with the optical read-out, acting above $10 \mathrm{kGy}$ has been presented. The sensor consists of a microchamber filled with small portion of high density polyethylene (HDPE) and thin silicon membrane. The principle of operation of the sensor is based on radiolysis effect of the HDPE which, upon radiation exposure, releases the hydrogen. The hydrogen increases the pressure inside the microchamber causing the deflection of the membrane, which is proportional to the pressure, thus to radiation dose. The sensor has been irradiated with high energy electron beam with dose 5 $\div 40 \mathrm{kGy}$. The displacement of the membrane has been detected by optical interferometer. The relative generated pressure inside the sensor chamber has been found very high (up to $180 \mathrm{kPa}$ ). It shows that response of a micro-scaled MEMS sensor is much more effective in comparison to macro-scaled solutions.
\end{abstract}

\section{Introduction}

According to the today's state of art, high-doses of radiation (above $10 \mathrm{kGy}$ ) may be only estimated post factum by a family of passive thermo-, radio- and photoluminescence indicators or hydrogen pressure dosimeters [1-3]. In situ measurements have been up-to-date obtained only for low or medium doses (below $10 \mathrm{kGy}$ ) by solid-state MOS based sensors.

The authors goal is to develop a new type of sensor for high-dose radiation measurements compatible with in situ readout methods. It will solve the problem of high-dose measurements in newly developed nuclear reactors with increased power [4] or in industrial accelerators as well as a research facilities like Large Hadron Collider. There is a great need for new, cheap, easy-to-use type of sensors, able to measure high doses of ionizing radiation (gamma and/or high energy electron beam) from several to hundreds of kGy [5].

The idea of MEMS sensor for measurement of high radiation levels above 10 kGy have been shown in our previous work [6]. In that solution, thin silicon membranes made over a reference chamber, filled with a pill of HDPE, had been deflected under pressure of $\mathrm{H} 2$, being the result of degradation of irradiated HDPE. Membranes crashed if the radiation dose reached the designed level. Concept of the MEMS threshold sensor has been confirmed.

In this paper we focused on proportional MEMS radiation sensor. The deflection of the membrane has been realized by interferometry optical detection method. The effects of HDPE degradation in microscale have been discussed here.

\section{Construction and fabrication}

As mentioned, the work principle of a MEMS sensor is based on radiolysis of HDPE. As a result of this phenomenon, released hydrogen causes drop of pressure (p1) inside encapsulated chamber and deflection of a thin silicon membrane. The pressure 1 must not exceed the pressure causing membrane destruction pmax (Fig. 1). The membrane deflection is proportional to the hydrogen pressure, thus to a radiation dose. This principle of the work stays behind a construction of the sensor schematically shown in Fig. 2a. Fabrication process is described below. First, (100) oriented, double side polished silicon wafer (4") is deeply micromachined in TMAH based wet etchant, to form a bossed membrane and container for HDPE (Fig. 2b,c). Following this, borosilicate glass wafer (1) is micromachined in liquid 
HF to form connecting channels (Fig. 2d). Next, the glass wafer (1) is anodically bonded (450 ${ }^{\circ} \mathrm{C}, 600$ V) to micromachined silicon wafer (Fig. 2e). After optical inspection of prefabricated structures, small portion of HDPE is manually inserted into the container (Fig. 2f). Finally, anodic bonding of a glass cover (borosilicate glass 2) is done. This is a key process of sensor manufacturing as bonding must be done without HDPE damaging that implies the use of at low temperature and anaerobic atmosphere. The optimal fabrication temperature must be kept below $340 \circ \mathrm{C}$ (degradation of HDPE 25213-02-9, Olefins and Polymers USA). Best results have been obtained for $300{ }^{\circ} \mathrm{C}, 1200 \mathrm{~V}$ and pure Nitrogen of about $100 \mathrm{kPa}$ of absolute pressure (Fig. 2g). Before HDPE introduction into MEMS structure, the outgassing procedure of the polymer is done. HDPE free of contaminant gases, includingH2O, is obtained. The final look of sensor is shown in the Fig. 3 . The sensor $(25 \times 11 \times 1.925 \mathrm{~mm} 3)$ consists of microchamber $(7.7 \mathrm{~mm} 3)$ filled HDPE $(2 \mathrm{mg})$ and a 80 m thick silicon membrane with planar dimensions $5 \times 5 \mathrm{~mm} 2$.

$$
\text { the sensor before irradiation }
$$

ionizing radiation
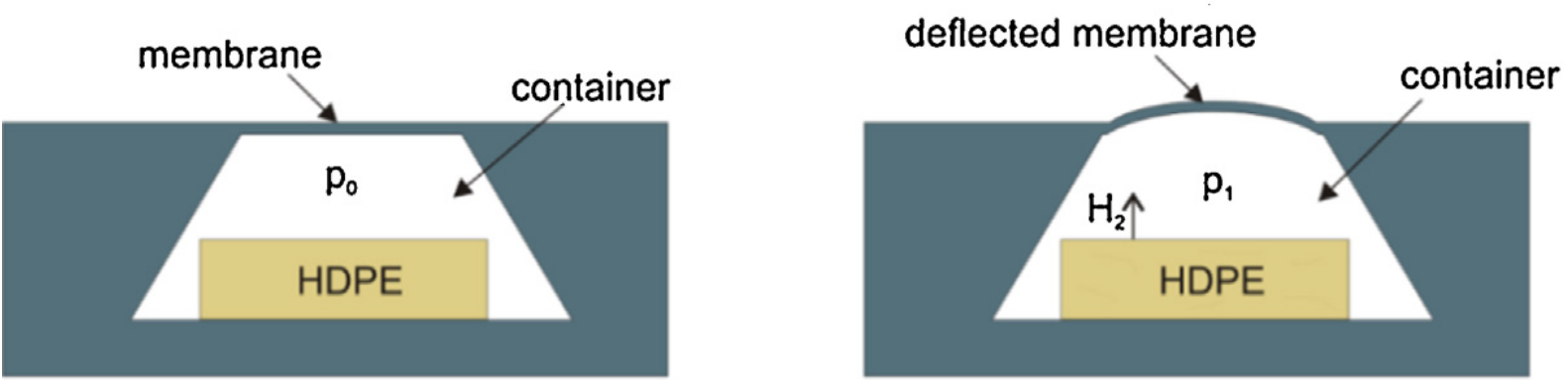

below maximal pressure/dose $p_{\max }$

Fig. 1. Principle of operation of the sensor [6]. 
a)

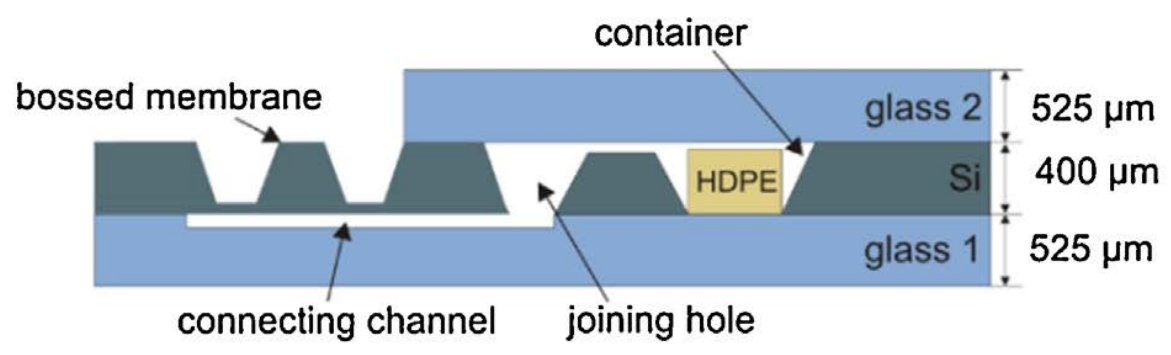

b)

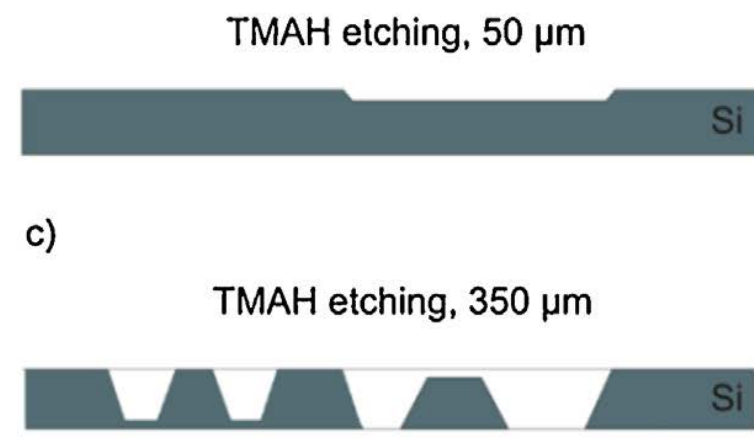

d)

HF etching, $10 \mu \mathrm{m}$ e) anodic bonding in air, $450^{\circ} \mathrm{C}, 600 \mathrm{~V}$

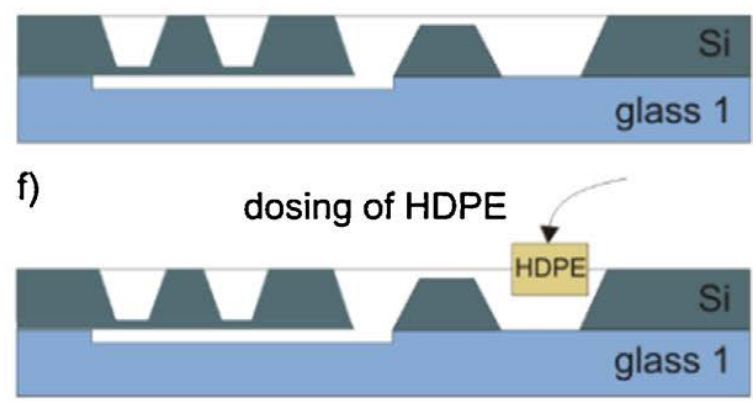

g)

anodic bonding in nitrogen, $300^{\circ} \mathrm{C}, 1200 \mathrm{~V}$

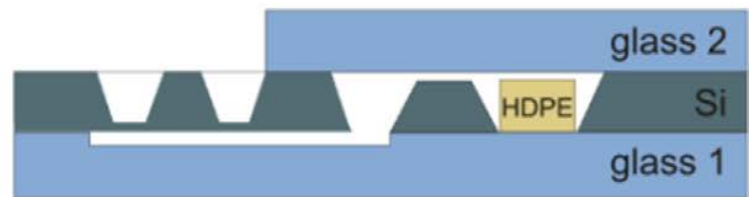

Fig. 2. Scheme of the construction of the sensor (a) and the fabrication steps: (b) etching the container in silicon; (c) etching the container in silicon and boss membrane; (d) etching a connecting channels in glass 1; (e) anodic bonding the silicon wafer with glass 1; (f) dosing the portion of HDPE to the container; (g) anodic bonding with lower temperature the silicon container filled with polymer and glass 2.

a)

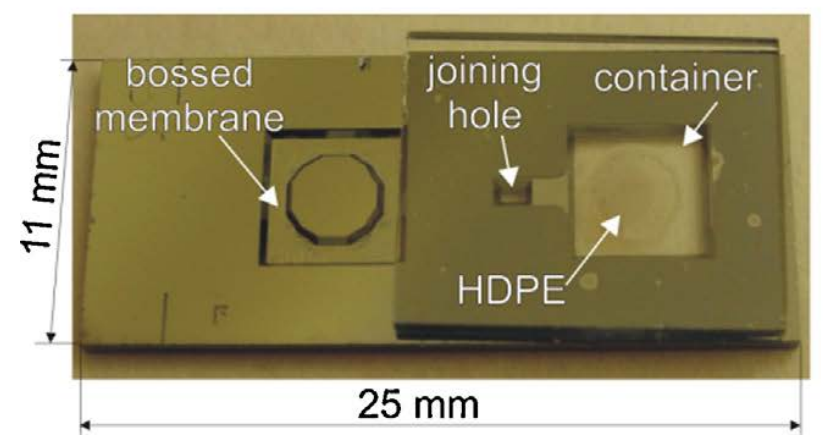

b)

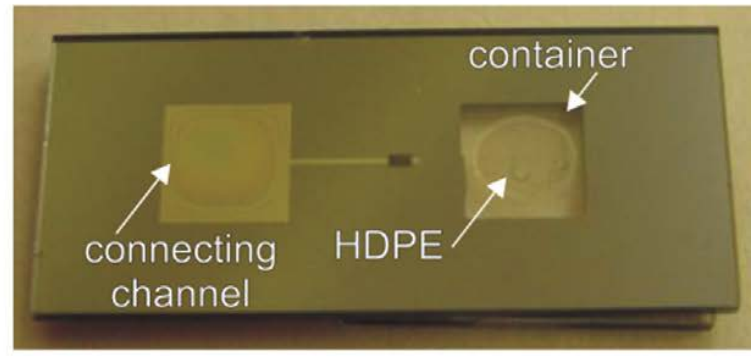

Fig. 3. Sensor at the glance: (a) top of the sensors; (b) back of the sensors. 
a)

cross-sectional view of the sensor after irradiation

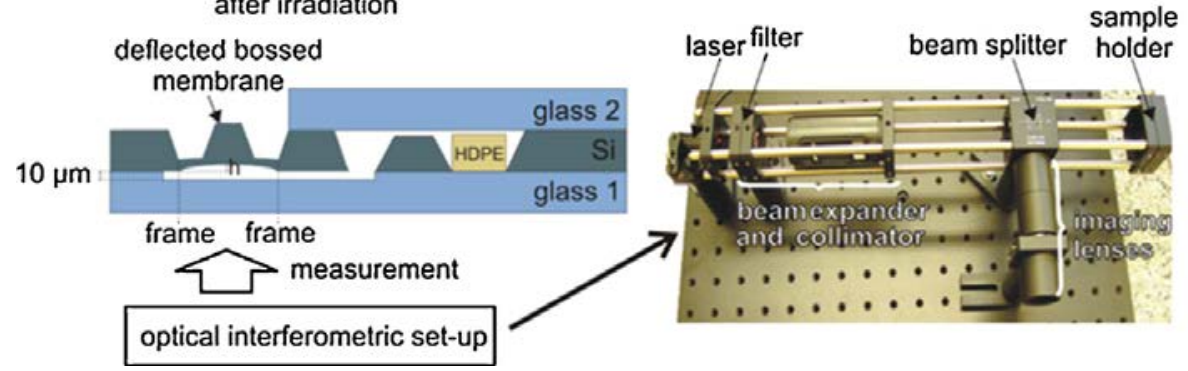

c)

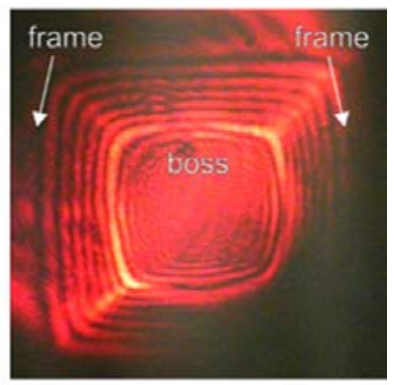

Fig. 4. Sensor and interferometric measurement set-up: (a) schematic of irradiated sensor; (b) view of the set-up; (c) sensor and interferometric views of boss membrane - deflection 3,79 $\mu \mathrm{m}$ for sensor irradiated by $30 \mathrm{kGy}$.

\section{Experiment}

Two parallel tests have been scheduled. MEMS sensors have been irradiated with different doses in range from $5 \mathrm{kGy}$ up to $40 \mathrm{kGy}$. Based on this tests a sensor characterization (membrane displacement versus dose of radiation) have been done. In parallel, calibration procedure of membrane displacement has been done in order to get correlation between $\mathrm{H} 2$ pressure inside the microchamber and membrane deflection after irradiation. In both tests interferometry optical measurements have been used (Fig. 4a). The membrane deflection has been measured in room temperature $\left(20{ }^{\circ} \mathrm{C}\right)$ by interferometric set-up (Fig. 4b) equipped with laser ( $5 \mathrm{~mW}, \lambda=633 \mathrm{~nm}$ ), beam expander and collimator, beam splitter and CMOS camera (camera resolution $1280 \times 1024$ ). An example of interferogram is shown in Fig 4c. Measurement error $\pm 0.32 \mu \mathrm{m}$ is counted as distance between the neighbouring fringes and depends strongly on laser wavelength. The displacement (h) of a membrane has been calculated from (1):

\section{$\mathrm{h}=\lambda \mathrm{m} / 2$}

where: $\mathrm{m}$ - number of fringes, $\lambda$ - wavelength of the laser.

The MEMS sensors have been irradiated on linear accelerator (6MV) by high energy electron beam with different doses in range from $5 \mathrm{kGy}$ up to $40 \mathrm{kGy}$ (National Centre for Nuclear Research in Poland). Dose were provided by pulsed electron beam of $\phi 3 \mathrm{~mm}$ spot with frequency $50 \mathrm{~Hz}$ directly to HDPE. Each sample has been irradiated once with defined dose from previously defined range. Several samples have been irradiated and post factum membrane displacement measurements have been done (Fig. 5). Nonlinear curve have been obtained. The full range of measurement has been divided into three regions. The sensitivity and resolution for each region have been collected in Table 1. Sensitivity has been calculated from (2):

$$
S=\frac{\Delta h}{\Delta d}\left[\frac{m}{1 K G y}\right]
$$

where: $\Delta \mathrm{h}$ - relative membrane displacement in range, $\Delta \mathrm{D}$ - relative dose of radiation in range. The total measurement error of membrane displacement $(0.64 \mu \mathrm{m})$ has been taken into consideration to calculate the sensor resolution (3):

$$
R=\frac{0.64}{S}[k G y]
$$

It is clearly visible, that the sensor resolution becomes better for increasing doses of radiation. The sensor temperature during irradiation has not been measured. The post factum characterization eliminates problem of the influence of the sensor temperature on pressure (displacement). This problem can be taken into consideration during on-line monitoring. However, heat generation caused by irradiation will 
be visible for irradiation utilized electron beam delivered high doses in short time (available in industrial linear accelerators only).

Several tests structures (sensors without HDPE), were fabricated specially for calibration of H2 pressure inside the micro chamber versus membrane deflection. Sensor membranes were moved up by compressed air pressure ( $0-200 \mathrm{kPa}$ of relative pressure; pressure controlled with high precision $0.05 \%$ FSO by Keller LEX1 pressure transducer) as shown in Fig. 6a. Membranes displacements for different pressure values have been noticed by interferometric set-up described before. Additionally, FEM modeling, using Comsol Multiphysics modelling software (solver: Structural Mechanics, Plane Stress), of membranes displacements versus applied pressure have been done. The experimental results and theoretical calculation are set together in Fig. 6b. Nonlinear shape of the curve explains results of membrane displacement versus dose previously presented in Fig. 5.

Based on FEM modelling, pressure increase per membrane deflection unit is $37 \mathrm{kPa} / 1 \_\mathrm{m}$. Having regard to the total error of displacement measurements $\left( \pm 0.32 \_\mathrm{m}\right)$, the error of pressure estimation based on displacement measurements is $\pm 12 \mathrm{kPa}$. This value will be important for subsequent discussion. Based on the experimental curves (Fig. 5 and Fig. 6b), H2 pressure inside micro chamber versus irradiation dose has been calculated (Fig. 7). The pressure inside the chamber PH2 after irradiation was from tens to hundreds of $\mathrm{kPa}$.

The measurements of membrane deflection have been done again two weeks later after irradiation. No pressure shifts have been noticed what indicate airtight sealing. The influence of the atmospheric pressure on the measurements has been estimated. The global pressure range from $970 \mathrm{hPa}$ to $1030 \mathrm{hPa}$ has been taken into consideration [10]. The whole World atmospheric pressure difference is $6 \mathrm{kPa}$. Normally, atmospheric pressure measured on continents oscillate between $1000 \mathrm{hPa}$ and $1020 \mathrm{hPa}(2$ $\mathrm{kPa}$ difference). If the atmospheric pressure has not been noticed during measurements, the maximum error of pressure estimation is $\pm 2 \mathrm{kPa}$.

The total error of pressure estimation equal $\pm 14 \mathrm{kPa}$ is a sum of the error of pressure estimation based on displacement measurements and error of possible atmospheric pressure influence. The total error must be taken into consideration for low doses. Its influence decreases when dose of radiation increases (Fig. 7).

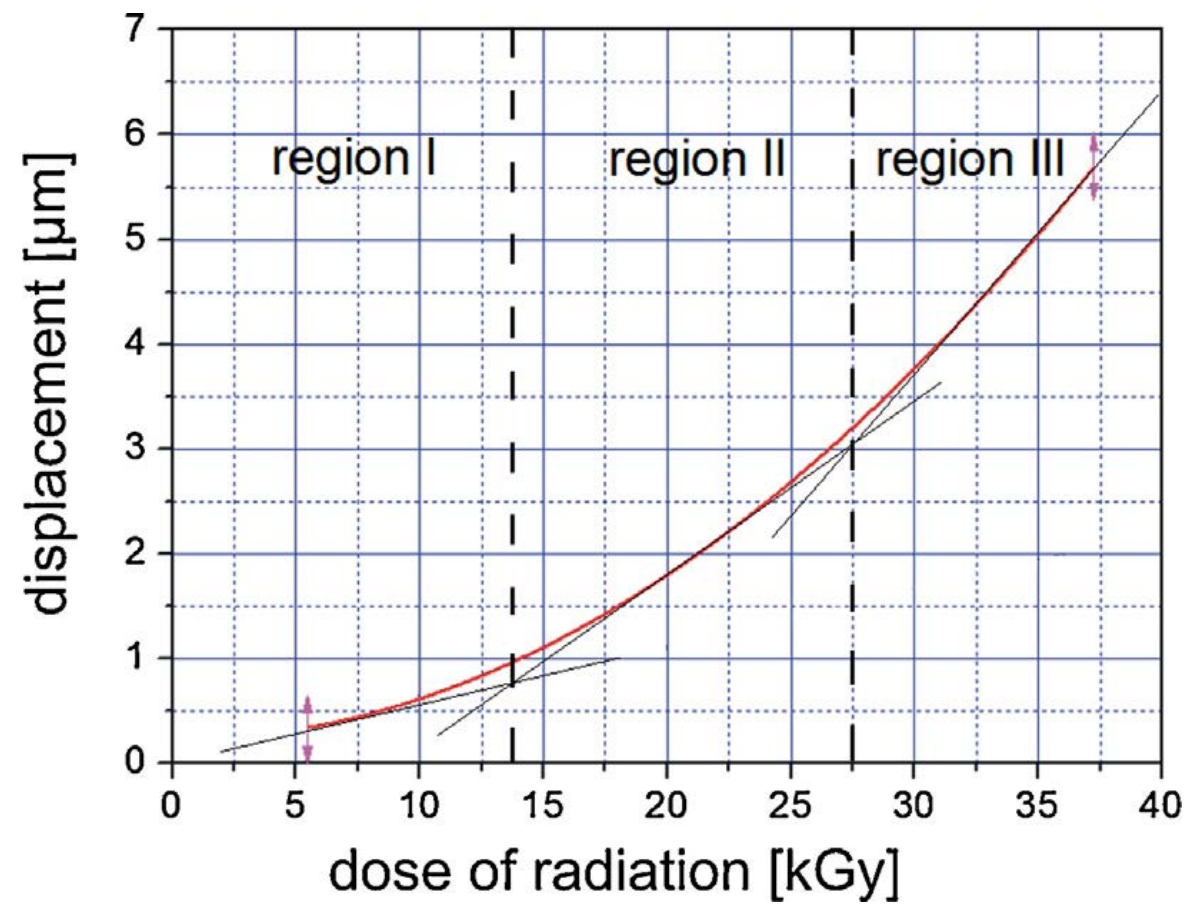

Fig. 5. Sensor response for $5 \times 5 \times 0.08 \mathrm{~mm} 3$ membrane: measured membrane deflection as a function of radiation dose. 

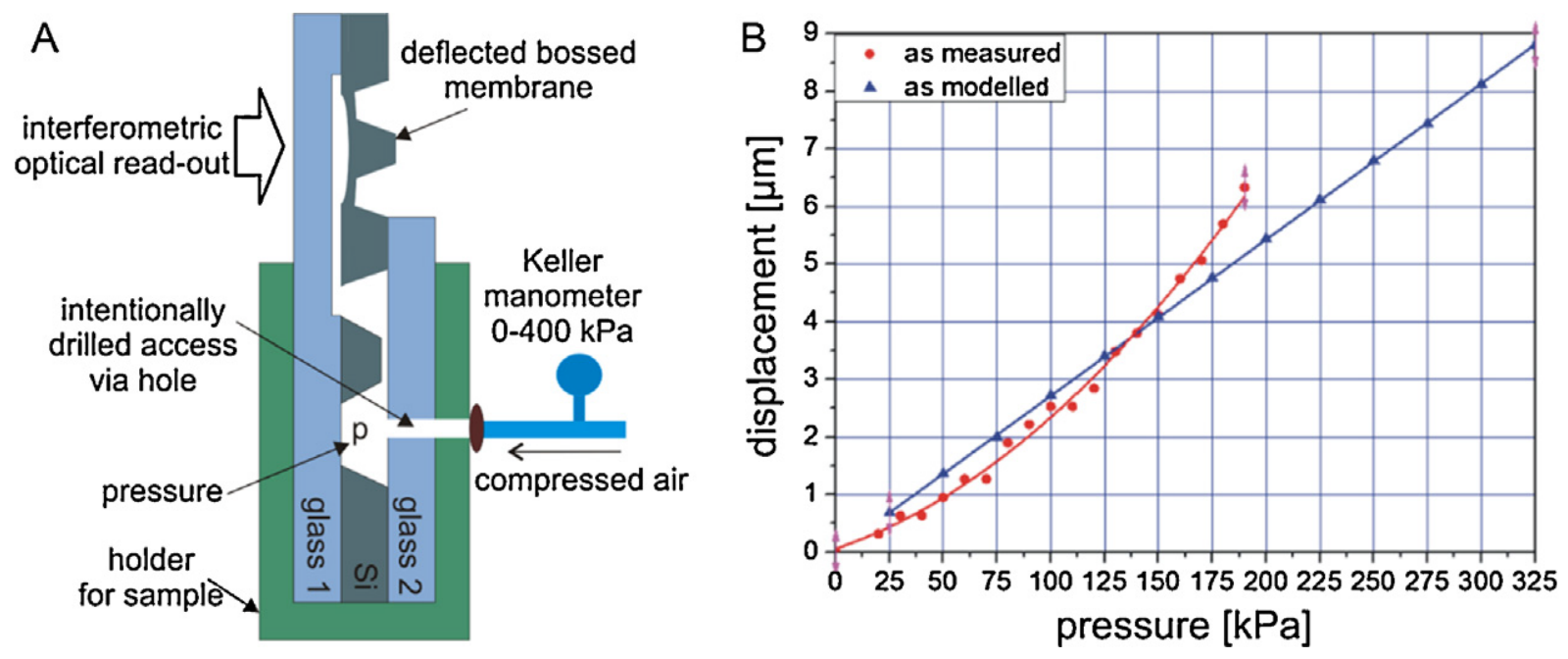

Fig. 6. Scaling procedure of the sensor: (a) measurement set-up for scaling; (b) deflection as a function of pressure inside the micro chamber.

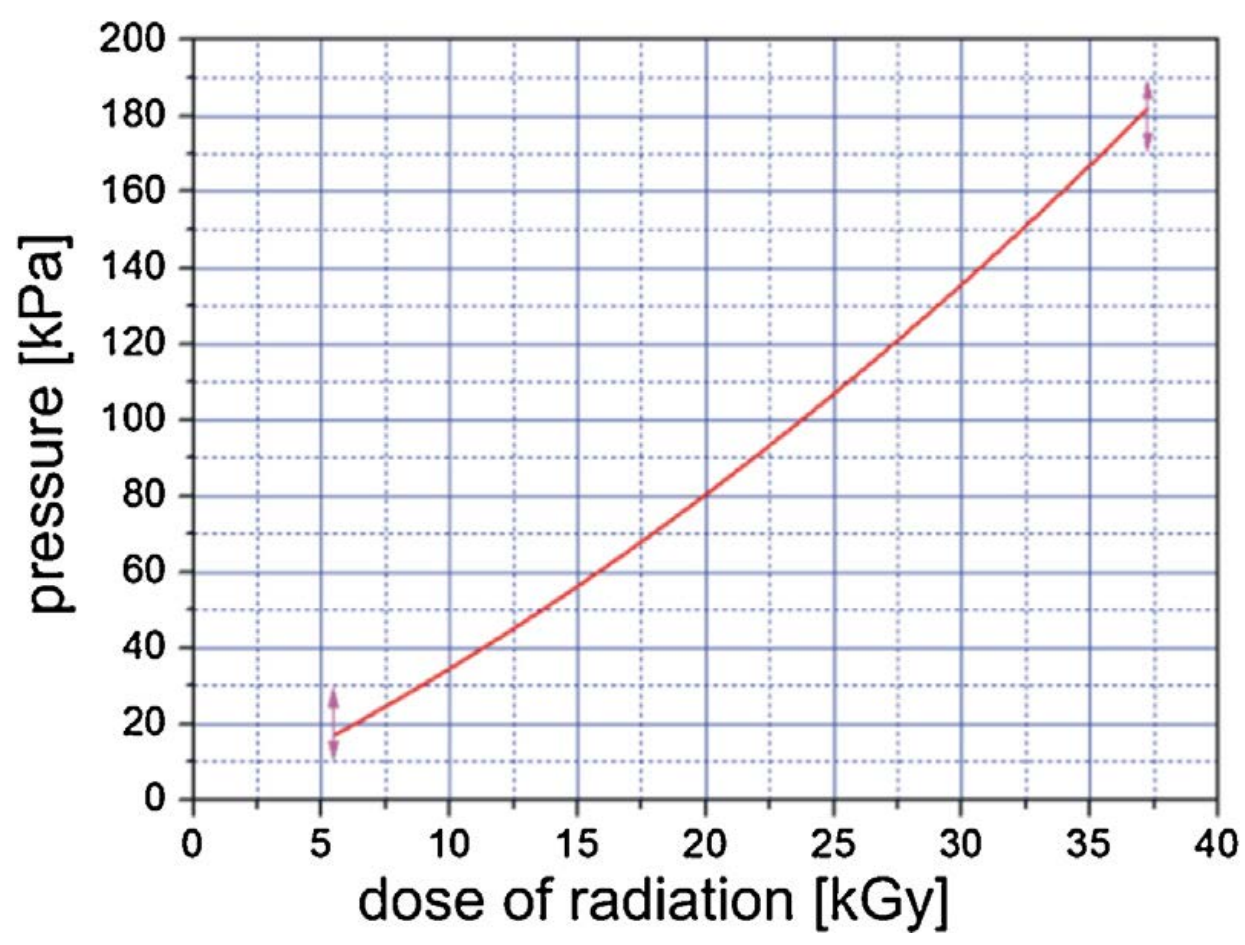

Fig. 7. Sensor response for $5 \times 5 \times 0.08 \mathrm{~mm} 3$ membrane: calculated pressure as a function of radiation dose.

\section{Discussion}

Discussion on efficiency of releasing of atomic hydrogen from polyethylene subjected a high dose of radiation as well as the amount of resulting pressure $\mathrm{P}_{\mathrm{H} 2}$ have been reported in several papers [7-9]. All this investigations have been done for macro-scaled detectors. According to a reference work [8] a Hydrogen pressure $\left(\mathrm{P}_{\mathrm{H} 2}\right)$ after irradiation $30 \mathrm{kGy}$ is $0.13 \mathrm{kPa}$ for the macro-sensor (quartz glass capsule $65 \mathrm{~mm}$ length and $12 \mathrm{~mm}$ diameter, chamber volume $5530 \mathrm{~mm}^{3}$ net, polyethylene film $0.25 \mathrm{~g}, \rho=0.92$ $\mathrm{g} / \mathrm{cm}^{3}$ ). We noticed much higher pressure $140 \mathrm{kPa}$ inside MEMS sensor (dimensions $25 \times 11 \times 1.925 \mathrm{~mm}^{3}$, container $5.6 \mathrm{~mm}^{3}$ net, high density polyethylene pill $0.002 \mathrm{~g}, \rho=0.95 \mathrm{~g} / \mathrm{cm} 3$ ) for the same irradiation level (30 kGy). Our results and those presented in [8] have been set together what it shown in Fig. 8. 
The relative pressure in MEMS container is more than 1000 times higher than in macro-scaled solution. The VPE/Vc ratio (4) for macro sensor is 0.049 and for MEMS sensor 0.375 :

$$
P_{g}(P a) \propto \frac{V_{P E}}{V_{\mathrm{C}}} / k G y
$$

where: $\mathrm{P}_{\mathrm{g}}$ - a relative Hydrogen pressure, $\mathrm{V}_{\mathrm{PE}}$ - volume of the polymer, $\mathrm{V}_{\mathrm{c}}$ - volume of the chamber.

The factor scale of MEMS container volume to macro container volume is about 987 . Thanks to miniaturization of the container and reducing the portion of the polymer relative pressure - a response for dose of radiation is thousand times higher than in macro sensor. Owing to the measurement of pressure is carried out in wide range with small error. Using MEMS sensor we can obtain sensors with reduced size but also high generated pressure that is easier to detect. The efficiency of the operation of the MEMS sensor is much better than in macro sensor.

Calculations of amount of gas in the containers after irradiation have been done. Based on Ideal gas law (5) the amount of hydrogen ' $n$ ' for ambient temperature $298 \mathrm{~K}$ has been calculated.

$$
n=\frac{P V}{R T}
$$

where: $\mathrm{n}$ - amount of substance of the gas, $\mathrm{V}$ - volume of the gas; $\mathrm{P}$ - pressure of the gas; $\mathrm{R}$ - the ideal gas constant; $\mathrm{T}$ - temperature of the gas.

The amount of hydrogen atoms in containers have been calculated based on volume of one mole for an ideal gas under standard conditions (1013 hPa, $298 \mathrm{~K})$. The amount of hydrogen molecules has been calculated for 1mg of polymer (Fig. 9a) and 1mm3 of container net volume (Fig. 9b).

The amount of hydrogen molecules generated during irradiation is significantly higher for MEMS structure. The type of polyethylene is not taken into account in above calculations.

Performed calculations explains rapid and high increase of relative pressure inside MEMS sensors. The same trend of pressure level changes is observed on data taken from experiment and calculation.

\section{Conclusion}

The silicon-glass MEMS high-dose radiation sensor with optical detection has been fabricated and tested. The sensor $\left(25 \times 11 \times 1.925 \mathrm{~mm}^{3}\right)$ consists of microchamber $\left(5.6 \mathrm{~mm}^{3}\right.$ net) filled with HDPE $(2 \mathrm{mg})$ and a silicon membrane with dimensions $5 \times 5 \times 0.08 \mathrm{~mm}^{3}$. Irradiated HDPE degrades, releasing hydrogen, which pressure is proportional to radiation dose. The sensor has been irradiated with high energy electron beam in range 5 $\div 40 \mathrm{kGy}$ by linear accelerator. The sensor response (membrane deflection) has been detected by interferometry set up. The pressure inside the sensor's container after irradiation has been found very high. The amount of pressure in MEMS sensor has been compared to macro sensor used from 1950s. It shows that micro-scaled MEMS sensor response is much more effective in comparison to macro-scaled solutions. Moreover, the miniaturization has great influence on the sensor scalability. Because of high pressure of generated hydrogen inside the MEMS structure, wide scaling of the sensor is possible by changing thickness of the silicon membrane. The use of high density polyethylene as indicator of radiation allowed receiving several times higher than in polyethylene amount of hydrogen molecules after irradiation. The sensor is a very good demonstrator how the pretty old principle "dressed" in a new microengineering formula gives, potentially attractive solution in a microscale. This is a new solution opening the way toward creation of family of high dose radiation MEMS for in situ, real-time measurements in harsh and dangerous conditions in which no other sensor could be applied. 


\section{Acknowledgements}

The presented work was co-financed by the European Union via National Centre for Research and Development and by Midi- Pyrénées Region - project FP7-MNT-ERA.NET-DOSIMEMS and Statutory Grant for Young Researchers of Wrocław University of Technology.

\section{References}

[1] K. Brabcová, I. Jadrnícková, A.G. Molokanov, et al., Dosimetry in heavy ion beams using various detectors, Radiat. Meas. 45 (2010) 1384-1386.

[2] M.H. Van de Voorde, Effect of radiation on materials and components - Megarad dosimetry, report CERN, 1969.

[3] J. Barthe, Electronic dosimeters based on solid state detectors, Nucl. Instrum. Methods Phys. Res. B 184 (2001) 158-189.

[4] B. Camanzi, A.G. Holmes-Siedle, The race for new radiation monitors, Nat. Mater. 7 (2008) 343345.

[5] F. Ravotti, M. Glaser, A.B. Rosenfeld, et al., Radiation monitoring in mixed environments at CERN: from the IRRAD6 facility to the LHC experiments, IEEE T. Nucl. Sci. 54 (2007) 1170-1177.

[6] I. Augustyniak, J. Dziuban, P. Knapkiewicz, et al., MEMS high-doses radiation sensor, in: The 17th International Conference on Solid-State Sensors, Actuators and Microsystems Barcelona, Spain, June 16-20, IEEE; 1503-1506, 2013.

[7] E.J. Lawton, P.D. Zemany, J. Balwit, Gases liberated during the high voltage electron irradiation of polyethylene, NOTES (1954) 3437-3439.

[8] M. Coche, F. Coninckx, H. Schonbacher, Comparison of high-dose dosimetry systems in accelerator radiation environments, Report of CERN TIS-RP/205 (1988).

[9] A. Singh, Irradiation of polyethylene: some aspects of crosslinking and oxidative degradation, Radiat. Phys. Chem. 56 (1999) 375-380.

[10] Website weather service: <https://www.meteoblue.com/en/weather/map/

Thickness pressure/world >; selected map type: pressure. 